Quanto à $2^{\mathrm{a}}$, NÃO. Considero que a Lei Complementar $\mathrm{n}^{\circ} 35$, de 1979 , no que respeita ao ingresso dos advogados e membros do Ministério Público, nos Tribunais, não alterou o critério para sua escolha, bastando se busque harmonizar suas disposições com as correspondentes da Constituição, às quais se devem submeter.

Quanto à $3^{\mathrm{a}}$, SIM. Penso que deve prevalecer, no pertinente, a interpretação do citado art. 144 e seus incisos, da Constituição, a exegese que lhes atribui o S.T.F., nas comentadas Representações $n^{\circ}$ s 879 e 881 , inobstante o que decidiu a mesma Corte, na Representação $\mathrm{n}^{\circ} 1.006$, contra quatro votos, não sendo de meu conhecimento que tal orientação tenha sido reiterada, em julgamento posterior e nova composição da Corte.

Quanto à $4^{\text {a }}$, NÃO. O mandado de segurança merece indeferimento, eis que o ato impugnado tem inteiro amparo na Constituição - art. 144, I, II, III e IV - e não destoa da Lei Complementar $n^{\circ} 35$, de 14-3-1979 - art. 100 seu $\S 4^{\circ}$, cujas disposições devem ser interpretadas em harmonia com os citados textos da Lei Maior

ÉoPARECER

Porto Alegre, 23 de novembro de 1983.

Carlos Thompson Flores

\title{
El convenio relativo a la protección del niño y la cooperación en materia de adopción internacional de La Haya y la adopción internacional en Alemania*
}

\author{
Dr. Christoph Benicke \\ Universidad de Heidelberg, Alemania
}

\section{Introducción}

1. Importancia de la adopción internacional

Las adopciones internacionales han tomado hoy día una gran importancia real. En Alemania el período donde por primera vez se efectuaron un considerable numero de adopciones internacionales fue después de la segunda guerra mundial ${ }^{1}$. Alemania estaba destruida, muchos niños habían perdido sus padres en la guerra y otros padres no se veían en capacidad de criar a sus propios hijos, por la condición social o económica. Los padres adoptivos provenían de los países ganadores de la guerra, sobre todo de los Estados Unidos.

Estas adopciones tienen todavía una cierta actualidad cuando los niños adoptados vienen a Alemania para buscar sus raices biológicas ${ }^{2}$. Además son de gran importancia en cuanto al derecho sucesorio. Cuando un pariente de la familia biológica muere, se cuestiona si estos niños adoptados forman parte de los herederos legales ${ }^{3}$. Estos casos son relativamente frecuentes debido a que los padres 0 los tíos biológicos hoy son de una edad muy avanzada: Familias que en aquellos tiempos eran muy pobres, pueden haber hecho una gran fortuna, que en el momento de la sucesión debe ser repartida.

\footnotetext{
Este es la versión escrita y ampliada de una conferencia dada el 11 de abril de 1997 en la Universidad Federal de Rio Grande do Sul.

Literatura citada en forma abreviata: Benicke. Typenmehrheit im Adoptionsrecht und deutsches IPR, Frankfurt/ Main 1995; Hohnerlein. Internationale Adoption und Kindeswohl, Baden-Baden 1991; Jayme, Kulturelle Identität und Kindeswohl im internationalen Kindschaftsrecht, IPRax 1996, $237 \mathrm{ss}$.: Krause, Adoption, International Encyclopedia of Comparative Law, VI ch. 6; Lima Marques, Das Subsidiaritätsprinzip in der Neuordnung des internationalen Adoptionsrechts, Frankfurt/Main 1997; Marx, Perspektiven der internationalen Adoption, Frankfurt/Main 1993; Parra-Aranguren, Rapport explicatif de la convention du 29 mai 1993 sur la protection des enfants et la cooperation en matière d adoption internationale, ed. Conference de La Haye de droit international privé; Trillat/Nabinger, Adopción internacional y tráfico de niños. Mito y realidad, R.I.P.C. 1991 , p. 18 ss.

Abreviaciones de revistas: FamRZ: Zeitschrift fuer das gesamte Familienrecht; IPRax: Praxis des Internationalen Privat- und Verfahrensrecht; NDV: Nachrichtendienst des Deutschen Vereins fuer oeffentliche und private Fuersorge, RablZ: Rabels Zeits Magnus/Münzel, Adoptionen von Kindern aus Ubersee, StAZ 1977, p. 66 s.; Silvermann/Weitzmann, Nonrelative Adoption in the United States, en Hoksbergen, Adoption in worldwide perspective, Berwyn 1986, p. 3 .

Ver los casos comunicados en el informe del Servicio internacional social en Alemania, Adoptierte suchen ihre

Ver la decisión del Bundesgerichtshof (Corte federal de Alemania) 14.12.1988, IPRax 1990, p. 55.
} 
A pesar de que estos casos causan cuestiones jurídicas interesantes, las adopcione que hoy en día se efectuan producen problemas más graves que piden con urgencia soluciones. En la actualidad los casos más frecuentes son las adopciones de niños de Latino América, de Asia y más recientemente, los niños de Europa de l'este. Los padres adoptivos provienen en su mayoría de los países de Europa occidental y de Norte-América ${ }^{4}$. Cada año se realizan, solamente en Alemania, aproximadamente 1.500 adopciones de niños extranjeros ${ }^{5}$. En esta cifra no están incluidas las adopciones de padres alemanes que se hicieron en el extranjero ${ }^{6}$.

Las causas por las cuales se efectuan tantas adopciones internacionales son bien conocidas ${ }^{7}$. Por un lado, en muchos países existe el problema de niños abandonados. Hay una alt tassa de natalidad. Las causas son las familias que fallan o que por pobreza no pueden dar la atención necesaria a sus hijos. Por otra parte, en los paises de Europa y Noteamérica hay muchas parejas que quieren adoptar un niño. Al mismo tiempo sólo muy pocos menores son dados en adopción en dichos países. Hay una variedad de causas para ésto: Por el alto control de la natalidad son menos frecuentes los embarazos involuntarios. Además están permitidos por la ley los abortos medicales. Otro aspecto es que ya no existen tantos prejuicios contra la madre soltera. Incluso existen muchas ayudas del estado o de organisaciones voluntarias para favorecer el que la madre soltera tengan mejore condiciones para criar sus hijos. Asi mismo, existe

${ }^{4}$ Marx, p. 17.

${ }^{5}$ En el año 19948.449 adopciones han sido decretado en total en Alemania; en 1.491 casos el niño adoptado tenía una nacionalidad extranjera; 1.044 de estos niños fueron adoptados por padres alemanes; 353 por padres de los cuales uno tenia la nacionalidad alemana y el otro una nacionalidad extranjera; en 94 casos los adoptantes

6 Si estos no fueron repetidos en Alemania como es la practica comun en Alemania; ver infra III.2.

7 Hohnerlein, p. 29 s.; Marx, p. 17 s.; Trillat/Nabinger, p. 18 ss.

${ }^{8}$ Wolff, Zur Übertragungsdynamik zwischen Adoptiv- und Herkunftsfamilie, en NDV 1988, p. 155 s.

9 Trillat/Nabinger, R.I.P.C. 1991, p. 22.

Revista da Faculdade de Direito da UFRGS, v. 21, Março/2002
En Alemania una pareja que quiere adoptar un niño tiene que esperar normalmente mucho tiempo hasta que una adopción se haga posible. En promedio general por un niño que se da en adopción, existen 20 solicitantes. De esta manera muchos solicitantes no tienen la perspectiva para ser elegidos. En Alemania existen ademas sólo pocas organisaciones estatales o de beneficiencia que sirven como intermediarios para las adopciones internacionales ${ }^{10}$.

Por este motivo muchos solicitantes comienzan a buscar otras posibilidades para encontrar un hijo adoptivo y están dispuestos a pagar mucho dinero para cumplir su deseo. A ésto se añade que muchas parejas prefieren adoptar un niño de muy poca edad. En la vía oficial por los intermediarios reconocidos los niños dados a la adopción son frecuentemente ya mayores o tienen problemas psicológicos o físicos. Éstas son las causas principales de la gran demanda de hijos adoptivos, que provoca, por su parte, el tráfico ilegal de menores. No existe duda alguna del perjuicio que ocasiona este tráfico ilegal a los mismos niños. Por lo tanto, es evidente la convicción de que hay que combartirlo.

El convenio de La Haya sobre la protección del niño y la cooperación en materia de adopción tiene como objetivo principal evitar este tráfico. Este convenio utiliza el mecanismo de la intermediación obligatoria de instituciones estatales o supervisados por el estado para que una adopción internacional se pueda efectuar.

Además del tráfico ilegal de niños la adopción internacional plantea problemas en cuanto al reconocimiento del laudo que creó la adopción. Cuando una adopción se hizo, por ejemplo, en Brasil, es muy importante para la protección del niño, que esta adopción sea también reconocida en Alemania, el país donde a familia adoptiva piensa a residir. Si la adopción no se reconoce el niño queda sin padres. En Brasil la adopción terminó los vínculos legales con los padres biológicos. Y en Alemania el niño no tendrá el estatus de hijo legal de los padres adoptivos.

En este articula quiero tratar estas dos problemáticas jurídicas de las adopciones internacionales y las soluciones que el convenio de La Haya propone. En una primera parte voy a presentar el convenio y sobre todo su mecanismo de cooperación. En una segunda parte quiero exponer los problemas que surgen en cuanto a las adopciones internacionales desde el punto de vista de Alemania como un país receptor de niños. Es por un lado, el reconocimiento de dictámenes extranjeros de adopción y por otro lado, las condiciones para ordenar una adopción internacional en Alemania. En la tercera parte trato las reglas del convenio en cuanto a estos problemas.

\section{El convenio relativo a la protección del niño y a la cooperación en materia de adopción internacional. Su mecansimo de cooperación}

\section{Origen, fundamentos}

El tema de la adopción internacional y de la necesidad de mecanismos de protección ya ha sido tematisado por organisaciones

${ }^{10}$ Ver la repuesta del gobierno federal alemán a una pregunta parlamentaria del grupo parlamentario del partido Die Grïnen“" el 27 de julio de 1990, Drucksache des Deutschen Bundestags 11/7618, p. 4; Hohnerlein, p. 31. 
internacionales desde los años $1950^{11}$. Fueron elaborados convenios internacionales que no tuvieron gran éxito en cuanto a las ratificaciones. Quiero mencionar por ejemplo, el convenio de la comisión de La Haya sobre la competencia, la ley aplicable y el reconocimineto de decisiones en materia de adopción del año $1965^{12}$ y la convención interamericana sobre los conflictos de leyes en materia de adopción de menores de la Organisación de los Estados Americanos, hecha en La Paz en el año $1984^{13}$

Al contrario de éstos, el nuevo convenio de La Haya promete tener un gran éxito ${ }^{14}$. Forma parte del nuevo tipo de convenios internacionales como lo es el convenio sobre los aspectos civiles de la sustracción internacional de menores del año $1980^{15}$. El mecanismo del convenio está centralizado en la cooperación internacional de las autoridades encargadas con el proceso preparativo de una adopción, y no tiene como objeto principal, de solucionar las problemáticas del derecho internacional privado ${ }^{16}$. Otro elemento importante es que en la elaboración de este

convenio participaron los estados tanto de orígen así como los estados de recepción de niños adoptados ${ }^{17}$.

Las reglas estan basadas en los principios para la adopción formulados en la convención sobre los derechos del niño de las Naciones Unidas ${ }^{18}$. Estos principios están estipulados en el art. 21 de esta convención. La adopción tiene que hacerse por un acto de la autoridad competente respetando las leyes y el procedimiento aplicable. La adopción en otro país puede ser considerada como otro medio de cuidar del niño, en el caso de que éste no pueda ser colocado en un hogar de guarda o entregado a una familia adoptiva, o no pueda ser atendido de manera adecuada en el país de orígen. Este es el principio de subsidiaridad de la adopción internacional ${ }^{19}$. Un niño que va a ser ser adoptado en otro país gozará de salvaguardias y normas equivalentes a las existentes respecto a la adopción en el país de origen. En caso de adopción en otro país la colocación no debe dar lugar a beneficios financieros indebidos para quienes participan en ella.

${ }^{11}$ Ver Hohnerlein, p. 259 ss.; por ejemplo los principios de un grupo de expertos, elaborados en un encuentro en Leysin, Suiza, 1960; UN-Declaration on Social and Legal Principles Relating to the Protection and Welfare of Children, del 3 de diciembre de 1986 (ver Fadiga, Adozione ed affidamento, en Beghé Loreti, L'adozione de minori nelle legislazioni europee, Milano 1986, p. 218); Art. 21 de la Convención de las Naciones Unidas sobre los derechos del niño, hecha en Nueva York el 20 de noviembre de 1989.

${ }^{12}$ Pirrung, Sorgerechts- und Adoptionsübereinkommen der Haager Konferenz und des Europarats, RabelsZ 57 (1993), p. 145

${ }^{13}$ Operetti Badán, Comentarios a la convención interamericana sobre conflictos de leyes en materia de adopción de menores (Instituto interamericano del niño) Montevideo 1986; Samtleben, Neue interamerikanische Konventionen zum Internationalen Privatrecht, RabelsZ 56 (1992), p. 10.

${ }^{14}$ Ver sobre los trabajos preparatorios Lima Marques, p. 211 ss.

${ }^{15}$ Ver Benicke, El Convenio sobre los aspectos civiles de la sustracción internacional de menores y su aplicación en los tribunales alemanes, $\mathrm{n}, \mathrm{p}$. $\mathrm{n}$.

${ }^{16}$ Ver Art. 1 lit. b del convenio; Parra-Aranguren, N. 65 s.

${ }^{17}$ Lima Marques, p. 244.

${ }^{18}$ Ver preámbula del convenio; Parra-Aranguren, N. 55; Jayme, p. 243.

${ }^{19}$ Lima Marques, p. 77 ss.

Revista da Faculdade de Direito da UFRGS, v. 21, Março/2002
En consecuencia el convenio de La Haya formula en el art. 1 sus objetivos tales como: establecer garantías para que las adopciones internacionales tengan lugar en consideración al interés superior del niño y al respeto a los derechos fundamentales que le reconoce el Derecho internacional y instaurar un sistema de cooperación entre los Estados contratantes que asegure el respeto a dichas garantías y, en consecuencia prevenga la sustracción, la venta o el tráfico de niños y asegurar el reconocimiento en los Estados contratantes de las adopciones realizadas de acuerdo con el convenio.

El principio de la subsidiaridad en cuanto a la adopción en general y a la adopción internacional en especial se encuentra en el prólogo del convenio diciendo: que cada estado debería tomar, con caracter prioritario, medidas adecuadas que permitan mantener al niño en su familia de origen y que la adopción internacional puede presentar la ventaja de dar una familia permanente a un niño que no puede encontrar una familia adecuada en su estado de origen.

\section{El ambito de aplicación del convenio}

El convenio se aplica por su objetivo y su mecanismo sólo en adopciones internacionales en el sentido interestatal, en las cuales el niño con su residencia habitual en un estado miembro, es adoptado por padres con residencia en otro estado contractante, Art. 2 par. 1. En consecuencia, el criterio decisivo no es la diferencia de las nacionalides entre el hijo y los padres adoptivos ${ }^{20}$. Los problemas mencionados anteriormente surgen cuando el menor es trasladado de un estado a otro después de la adopción o para efectuar la adopción. Las reglas de un estado fallan cuando

${ }^{20}$ Parra-Aranguren, N. 71; Lima Marques, p. 252 ss. intentan protejer al menor en caso de un traslado a otro estado.

\section{El mecanismo de cooperación}

El mecanismo de cooperación del convenio. Este mecanismo es el nucleo del convenio. Como ya fue mencionado las las cuestiones del derecho privado no son el objeto principal de este convenio. Similar al convenio sobre los aspectos civiles de la sustracción aborda el problema de una manera práctica por cooperación de entidades administrativas.

En un proceso de adopción el acompanamiento y la supervisión por instituciones competentes y especializadas son de suma importancia para la protección de los intereses del menor así como para un buen resultado de la adopción en general. La adopción coloca al hijo como a los padres adoptivos en situaciones muy exigentes en las que necesitan una buena preparación psicologica y social. Este existe aún, en el caso de una adopción interna sin diferencia de culturas y tiene todavía más importancia en adopciones internacionales.

Una cooperación obligatoria en la etapa de la preparación de la adopción parece ser el mecanismo más eficaz contra el tráfico de menores. La cooperación administrativa puede servir como medio preventivo. Aunque ahora en casí todos los estados la adopción se dicta por una entitad estatal, un tribunal o un organismo administrativo, y que éste tiene como criterio decisivo el interés superior del niño, este procedimiento no puede impedir el tráfico ilegal de niños o adopciones inadecuadas.

En el momento de que el tribunal llega a encargarse del asunto, por lo general el niño ya 
esta viviendo con los futuros padres. Solamente cuando los solicitantes sean totalmente ineptos, el juez competente podría negar la adopción. En todos los demás casos, la adopción tiene que ser acordada por el propio interés del niño. Los padres biológicos son desconocidos o no pueden ser encargados del cuidado del niño por otras razones, el niño ya se acostumbró a los solicitantes y por el interés de éste hay que evitar una nueva ruptura. Aun en el caso que el juez sabe que los solicitantes han pagado a los padres biológicos o a otras personas intermediarias, la adopción parece siempre más favorable para el menor que de ser colocado en asilo cuando los solicitantes prometen de procurarle un hogar. El problema se plantea de manera parecida, como en el caso de la sustracción. El abuso de leyes no puede ser combatido en el caso concreto. Se necesitan medidas que tengan efectos preventivos. El convenio crea por medio la cooperación obligatoria un mecanismo que tiene como objetivo impedir que una adopción se pueda decretar, sin que un acompanamiento adecuado haya sido efectuado.

\section{Procedimiento de cooperación}

El convenio establece un procedimiento específico, que debe ser cumplido antes de que se dicte una resolución de adopción ${ }^{21}$. La norma clave es el art. 17. Este artículo exige la condición de que el niño solo puede ser confiado a los futuros adoptantes cuando las autoridades centrales de ambos estados hayan dado su acuerdo. Confiar al niño signífica no sólo la resolución de adopción, sino también la entrega del niño al los futuros adoptantes para posibilitar un tiempo de prueba.

El fin de la condición de que las dos autoridades centrales tienen que dar su acuerdo es de asegurar de una manera preventiva que el

niño no establezca una relación personal con los solicitantes que después solo puede ser rota con el consiguiente perjuicio para el menor. Así se evita que los solicitantes puedan establecer hechos en su favor que tienen que ser aceptados por el interés superior del niño al momento de dictar la adopción.

Antes de que las autoridades centrales puedan dar el acuerdo debe seguirse un procidiemiento de cooperación entre ellas. El convenio obliga a los solicitantes a dirigirse a la autoridad central del estado de su residencia habitual (art. 14).

Esta autoridad central tiene que averiguar si los solicitantes son adecuados y aptos para adoptar y si han sido convenientemente asesorados (art. 5). En el caso de un resultado positivo la autoridad central prepará un informe que transmitirá a la autoridad central del estado en el cual los solicitantes quieren adoptar un niño. Este informe debe contener la información relevante sobre los solicitantes como también sobre los niños que ellos están en condición de tomar a su cargo (art. 15).

Por su lado, la autoridad central del estado de la residencia habitual del niño tiene que averiguar si es adoptable y que una adopción internacional responde al interés superior del menor. Debe asegurarse que las personas o instituciones que tienen que consentir a la adopción han dado estos consentimientos libremente e informadas de las consecuencias y que éstas no se dieron por pago. Además se asegura que la adopción corresponda a los deseos y opiniones del niño tomando en cuenta su edad y grado de madurez (art. 4).

La autoridad central del estado de la residencia habitual del niño prepara un informe con toda la información esencial en cuanto a la

${ }^{21}$ Ver Lima Marques, p. 257 ss.

Revista da Faculdade de Direito da UFRGS, v. 21, Março/2002

persona del niño y en el caso constata que la colocación prevista obedece al interés superior del niño. Este informe y una prueba de que se han obtenido los consentimientos requeridos y la motivación de la decisión relativa a la colocación se tramsmiten a la autoridad central del estado de recepción.

El procedimiento se caracteriza por una distribución de las investigaciones y trabajos preparatorios entre las dos autoridades centrales. La autoridad central del estado de origen puede averiguar mejor si el interés superior del niño que vive en su territorio amerita una adopción internacional y si los consentimientos necesarios por parte de la familia del niño se han declarados de una manera libre y conciente. Al otro lado la autoridad central del estado de recepción puede estudiar mejor la aptitud del los solicitantes que residen en el mismo país y puede comprobar que el niño puede ser acogido en este estado. Por esta distribución de los trabajos preparatorios los estudios pueden ser más exactos. Además la obligación de los solicitantes de dirigirse a la autoridad central del estado de su residencia habitual asegura que ellos están acompanados y aconsejados. Cuando la autoridad central no los considera aptos la adopción no se puede llevar a cabo.

En general es muy importante que el convenio excluye el hecho de que los solicitantes se dirigen directamente a las autoridades del estado en el cual quieren adoptar un niño o que se llevan un niño sin procedimiento anterior al estado de su residencia habitual para solicitar la adopción en éste. El convenio obliga a los adoptantes de dirigirse a las autoridades estatales o entidades

privadas especialisadas para la intermediación y el acompanamiento. Las adopciones directas están muchas veces ligadas con el tráfico de menores $^{22}$. Un intermediario procura a los solicitantes, un niño a cambio de un pago. Y también por un pago los padres biológicos dan su hijo a la adopción.

El aspecto negativo de este procedimiento obligatorio es que hace los tramites de adopción todavía más largos, complicados y costosos. La predominancia del interés del niño en que la adopción resulte ventajosa y que el menor no sea objeto de un negocio comercial, justifica en mi opinión la agravación. El éxito del convenio depende de que la cooperación entre las autoridades centrales funciona de una manera eficaz.

Se puede criticar que el convenio se aplica también en el caso de una adopción entre parientes. Por ejemplo en el caso que el tío quiere adoptar sus sobrinos huérfanos que residan en otro país. En estos casos no existe la misma situación como por las adopciones internacionales regulares con el peligro del tráfico de menores que justifica un procedimiento tan sofisticado.

Otra particularidad que merece a ser notada es la importancia del procedimiento delante las autoridades centrales en cuanto al dictamen de la adopción. En el procedimiento preparatorio de la adopción las autoridades centrales se averiguan de todas las condiciones sociales, psicológicas y hasta de derecho para la adopción ${ }^{23}$. De esta manera el dictamen de la adopción por un tribunal se vuelve únicamente una formalidad. La decisión de si la adopción se puede efectuar ha sido tomada de hecho, por las autoridades centrales.

${ }^{22}$ Lima Marques, p. 135 ss.

${ }^{23}$ Parra-Aranguren, N. 337. 
III. La problemática jurídica de adopciones internacionales

\section{en Alemania}

Después de haber presentado la estructura del procedimiento administrativo previsto por el convenio, quiero ahora tratar los problemas puramente jurídicos que surgen de adopciones internacionales. Quiero dar primero un resumen de los problemas más frecuentes que se presentan en Alemania Después voy a analizar el reglamento del convenio en este aspecto.

\section{El reconocimiento de una sentencia de adopción}

En lo siguiente voy a concentrarme al caso más común que una pareja alemana quiere adoptar un niño de otro país. Primero voy a tratar los problemas del reconocimiento de una sentencia de adopción.

En la mayoría de los casos el país de orígen del niño exige que la adopción se efectue antes de que el niño pueda ser trasladado al país de la residencia habitual de los adoptantes. Cuando los padres adoptivos llegan con el hijo a Alemania se plantea, si esta adopción efectuada en el país de origen del menor puede ser reconocida en Alemania ${ }^{24}$.

Antes las condiciones para el reconocimiento no estaban establecidas por la ley y por consecuencia eran dudosas. En el año 1986 fue introducida una norma especial para $\mathrm{e}$

${ }^{24}$ Benicke, p. 167 ss.

${ }^{25} \S 16$ a Gesetz ueber die Angelegenheiten der freiwilligen Gerichtsbarkeit (ley sobre la jurisdicción voluntaria). ${ }^{26}$ Hohnerlein, p. 50 ss.

${ }^{27}$ Ver sobre los reglamentos en los diferentes estados europeos $\underline{\text { Hohnerlein, }}$ p. 146 ss.

${ }^{28}$ Benicke, p. 212 ss.

${ }^{29}$ Krause, N. 177 ss.

Revista da Faculdade de Direito da UFRGS, v. 21, Março/2002 reconocimiento de sentencias extranjeras en materia de la jurisdicción voluntaria ${ }^{25}$.

Esta norma es muy favorable al reconocimiento ${ }^{26}$. La condición escencial es que el tribunal extranjero ha tenido competencia internacional desde punto de vista alemana y que la adopción no esté en oposición con el orden público en Alemania. Para la competencia internacional es suficiente que el menor o la persona que solicita la adopción tenía su residencia habitual en el estado del tribunal o era nacional de este estado.

El reconocimiento se hace ex lege, es decir, no se necesita llevar a cabo un proceso judicial de reconocimiento. Este punto es a un lado favorable para el reconocimiento de la adopción extranjera. Pero la falta de un procedimiento en el cual la validez y los efectos de una adopción extranjera pueden ser determinados de una manera vinculante es una desventaja enorme en la práctica ${ }^{27}$

Existe en Alemania en la práctica de los tribunales una gran inseguridad hacia la validez y los efectos de las adopciones extranjeras. El reconocimiento ex lege significa que la validez de la adopción tiene que ser apreciada cada vez de nuevo cuando la cuestión se plantea.

Además existe inseguridad en cuanto a los efectos de la adopción ${ }^{28}$. La adopción crea por acto jurídico una nueva relación familiar entre el adoptante y el adoptado cambiando así el estatus personal del adoptado. El problema resulta del hecho que en los diferentes ordenes jurídicos la adopción cambia en diferentes grados las relaciones familiares ${ }^{29}$.
La diferenciación más común es la que se da entre la adopción plena y la adopción simple. La adopción plena disuelve todas las relaciones jurídicas con la familia biológica y integra el adoptado plenamente en la familia del adoptante. La adopción simple crea por lo general sólo relaciones jurídicas con la persona del adoptante y no disuelve todas las relaciones jurídicas con la familia biológica. Entre estos dos tipos existe una variedad de diferentes formas de adopciones. Hay una multidud de diferencias: La adopción plena en un estado no es lo mismo como la adopción plena en otro estado. El reconocimiento de una adopción extranjera está por esto siempre ligado con la cuestión qué efectos ésta produce.

\section{La repetición de adopciones}

La inseguridad en cuanto a los efectos y la necesidad de probar la validez de la adopción extranjera son las causas por las cuales en práctica las adopciones se vuelven a dictar por un tribunal alemán aplicando el derecho alemán ${ }^{30}$. Esta repetición convierte la adopción extranjera en una alemana. De esta manera no existe inseguridad en cuanto a los efectos y a la validez de la adopción.

La necesidad practica de repetir las adopciones es costosa y causa muchos otros problemas. Así el tribunal no está en la posición de negar la adopción con la excepción de casos muy graves. Por lo general el hijo adoptivo ya está viviendo con los adoptantes y los padres biológicos son desconocidos o no dispuestos a recoger al menor.
Pero resulta muy difícil cumplir los requisitos judiciales que exige la ley alemana para dictar la adopción. Segun el derecho internacional privado de Alemania la ley aplicable a una adopción es la ley personal del adoptante, en caso de una pareja casada la ley que rige las relaciones matrimoniales ${ }^{31}$. En la mayoría de los casos parejas alemanas adoptan a un niño extranjero. Por esto la ley aplicable es el derecho alemán. Para los consentimientos de la familia biológica es además aplicable también la ley personal de menor ${ }^{32}$

La adopción de un niño con origen de otro país causa muchos problemas en la práctica porque el derecho de adopción en Alemania y en otros estados está hecho para casos internos y no toma en cuenta las particularidades de casos internacionales.

Especialmente problemáticos son los consentimientos de la familia biológica del niño ${ }^{33}$. Muchas veces el consentimiento que la madre o el padre han dado a la adopción que se efectuó en el país de origen del menor no son válidos para decretar una adopción en Alemania. El consentimiento de la madre no se puede dar legalmente antes de ocho semanas después del nacimiento del menor. Si la madre ha manifestado su acuerdo seis semanas después del nacimiento, como está previsto legalmente en el país de origen, una nueva declaración de la madre es necesaria para que la adopción se pueda dictar de nuevo en Alemania. Como el consentimiento tiene que ser dirigido directamente hacía el tribunal competente muchas aprobaciones que se dieron en un

\footnotetext{
${ }^{30}$ von Bar, Internationales Privatrecht, Band 2, Muenchen 1991, N. 319; Henrich, Internationales Familienrecht, Frankfurt/Main 1989, p. 311

${ }^{31}$ Art. 22 Einfuehrungsgesetz zum Buergerlichen Gesetzbuch (ley preliminar al código civil); ver Baumann, Verfahren und anwendbares Recht bei Adoptionen mit Auslandsberührung, Bielefeld 1992, p. 17 ss.

${ }^{32}$ Art. 23 Einfuehrungsgesetz zum Buergerlichen Gesetzbuch (ley preliminar al código civil).

${ }^{33}$ Hohnerlein, p. 221 ss.; Benicke, p. 74 ss.
} 
procedimiento delante de un juez en el país de orígen sin haber sido documentadas no son suficientes para dictar la adopción en Alemania. Se puede prescindir el consentimiento de los padres biológicos sólo bajo condiciones muy estrictas.

Por eso en muchos casos los padres adoptivos tienen que procurar otra vez el acuerdo de la madre o del padre biológicos. Esto es muy complicado; los padres no ven la necesidad de consentir una segunda vez. Además como el consentimiento es un acto psicológico difícil para los mismos padres. En otros casos los padres biológicos sólo estan dispuestos a consentir de nuevo cuando reciben otro pago.

IV. Las reglas del convenio en cuanto al reconocimiento de sentencias extranjeras y de los consentimientos de los padres biológicos

Después que he demostrado un resumen de los dos problemas jurídicos principales que adopciones de niños extranjeros plantean en Alemania quiero volver al estudio del convenio. Quiero analizar las reglas sobre el reconocimiento y sobre las condiciones de base para dictar una adopción.

\section{El reconocimiento}

Primero quiero tratar el reconocimiento de una decisión de adopción. El art. 23 constata que una adopción que se hizo conforme al convenio tiene que ser reconocida de pleno

derecho en todos los estados contratantes. Unicamente se necesita que la autoridad competente del estado donde se dictó certifique la conformidad al convenio especificando cuando las autorizaciones de las autoridades centrales han sido otorgadas. El convenio prescribe así la obligación de reconocimiento sin que un procedimiento o el exequatur sean necesarios ${ }^{34}$.

Como el ejemplo de la regla alemana demuestra el reconocimiento ex lege es importante pero no suficiente para asegurar una situación jurídica estable y segura para el niño. Siempre pueden quedar dudas en cuanto a los efectos que esta adopción produzca en el ámbito del orden jurídico del estado de recepción.

El art. 26 del convenio especifica el significado del reconocimiento en cuanto a los efectos de la adopción. En las letras a y b este artículo comprueba la evidencia que el reconocimiento de una adopción contiene el reconocimiento del vínculo de filiación entre e niño y sus padres adoptivos y de la resposabilidad de los padres adoptivos respecto a su hijo. Estos son los efectos básicos de cada adopción. El convenio determina su ámbito de aplicación para adopciones que establecen un vínculo de filiación.

Los problemas no son tanto si se estableció algún vínculo de filiación. El estatus de ser hijo de una persona es algo abstracto. Tiene importancia real sólo por los efectos que resultan de él. Por ser padre del hijo adoptivo el padre adoptivo tiene el derecho de custodia. Las cuestiones difíciles surgen en cuanto a estos efectos concretos: ¿Se le acredita al niño el apellido del padre adoptivo? ¿Si la madre de padre adoptivo muere, es llamado heredero legal el niño adoptivo? ¿Puede el padre adoptivo hacer valer un derecho alimentício contra su hijo adoptivo? La base de la problemática es que los diferentes ordenes jurídicos aunque todos establecen un vínculo de filiación diferen sustancialmente en estos diferentes efectos ${ }^{35}$

Fue propuesto en Alemania que el reconocimiento transforme la adopción establecida en el extranjero en una adopción del derecho interno ${ }^{36}$. Esto significaría por ejemplo que una adopción que fue fundada en un cierto orden jurídico y que según estas leyes no establece un derecho sucesorio del padre adoptivo cambiaría y podría crear un derecho sucesorio del padre adoptivo como previsto en el derecho alemán.

Contra tal transformaticón hay que objetar $^{37}$ la naturalezza del acto de establecimiento de la adopción. La adopción se crea por un acto jurídico. Condición esencial para la fundación son los consentimientos de los padres biológicos, del niño y de los adoptantes. Se dan tomando en cuenta los efectos que la adopción produzca. Esto es óbvio en el caso del consentimiento de la madre biológica para una adopción simple. La adopción simple no termina las relaciones jurídicas con la familia biológica pero crea encima de éstas un vínculo de filiación con el padre adoptivo que obtiene por esto el derecho de custodia. Tal adopción no puede ser transformada en una adopción plena que termina todas relaciones jurídicas con la madre biológica. Estos efectos no encontrarían su base en el consentimiento de la madre biológica.

El convenio favorece la solución de una transformación limitada. En el art. 26 párrafo 2 declara que una adopción que tiene como efecto la ruptura del vínculo preexistente de filiación, el niño gozará en el estado contractante donde se reconozca la adopción, de derechos equivalentes a los que resultan de una adopción que produzca tales efectos en este estado.

Esto significa que una adopción que puede ser calificada como plena, porque termina la relación jurídica con la familia biológica según el orden jurídico del cual emaneció, es igualdada con la adopción plena del derecho del estado reconociente.

Esto parece una buena solución ${ }^{38}$. Al dar el consentimiento es de importancia para la familia biológica si la adopción rompe el vínculo de filiación o lo mantiene. Los detalles de los diferentes efectos en cuanto a la relacion con la futura familia adoptiva no son decisivos. Al otro lado la transformación en una adopción interna equivalente trae más seguridad. Sólo hay que probar que la adopción que se dictó es válida y plena. Para los distintos efectos no hay que recurir al oden jurídico del establecimiento de la

${ }^{34}$ Parra-Aranguren, N. 402.

Revista da Faculdade de Direito da UFRGS, v. 21, Março/2002

${ }^{35}$ Krause, N. 177 ss.

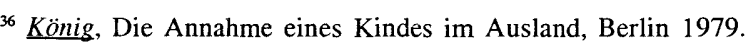

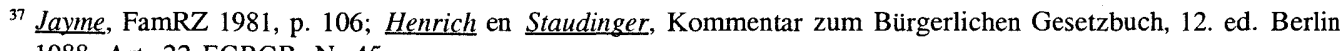
1988, Art. 22 EGBGB, N. 45.

${ }^{38}$ Bien que surge otro problema (ver Benicke, p. 327 s.): Las adopciones dictadas por tribunales alemanes pueden tener diferentes efectos, según la ley aplicable por el derecho internacional privado. Así en Alemania no existe una adopción interna unica. Los efectos dependen de la ley aplicable. El reglamento de la transformación fue propuesto por la Suiza (ver $\frac{\text { Parra-Aranguren, N. N63) donde la competencia de los tribunales está siempre }}{\text { ligada con la aplicación del derecho de adopción suizo. Cuando un tribunal suizo dicta una adopción, siempre }}$ ligada con la aplicación del derecho de adopción suizo. Cuando un tribunal suizo dicta una adopción, siempre aplica la ley suiza de adopción (Heini et al., Kommentar zum Bundesgesetz ueber interantionales Privatrecht, Zuerich 1993, Art. 78, N. 15. 
adopción, pero se puede recurrir al derecho del estado reconociente ${ }^{39}$

En cuanto a la inseguridad sobre la validez de una adopción hecha en el extranjero el convenio procura también una mejoría. Éste no prescribe un procedimiento en el cual la validez puede ser probada para todos las autoridades de un estado. Más bien impone a los estados contratantes la obligación de reconocer la adopción ex lege. En la práctica la certificación de la autoridad central del estado donde la adopción a tenido lugar puede servir como documento suficiente que facilita a los adoptantes y al adoptado de probar la validez de la adopción ${ }^{40}$. Una ayuda suplementaria para los comercios jurídicos se puede lograr si la autoridad central califica en esta misma certificación que se trata de una adopción plena.

\section{Efectos del convenio sobre los requisitos para dictar una adopción}

El convenio no contiene directamente reglas de derecho que estipulan las condiciones jurídicas para dictar una adopción. Pero en la práctica tendrá tiene remarcadas influencias en cuanto a los requisitos jurídicos de una adopción $^{41}$.

Estos efectos indirectos a los requisitos provienen del art. 17 lítera $\mathrm{c}^{42}$. Una adopción interestatal puede hacerse únicamente si el

procedimiento de cooperación de las autoridades centrales se ha llevado a cabo anteriormente y si existen los acuerdos de ambas autoridades centrales de que se siga el procedimiento de adopción (art.17 lit. c). La exigencia de un procedimiento detallado anterior al proceso judicial de dictar la adopción da al primero más importancia y reduce el papel del juez que dicta la adopción. El dictamen que era antes el acto decisivo se convierte practicamente en una pura confirmación de las deciones tomadas por las instituciones que preparan y acompañan el proceso preparatorio.

Esto se debe sobre todo por el hecho que las autoridades centrales no sólo se ocupan de las condiciones sociales, económicas y psicológicas de la adopción pero se averiguan también si las exigencias de ley están cumplidas $^{43}$.

La autoridad central del estado de orígen indaga si los consentimientos se han dado como requiere la ley. Además comprueba que el niño puede ser adoptado. La adoptabilidad contiene además de los aspectos psicológicos y sociales que las condiciones de ley permite la adopción de este niño. Por ejemplo el requisito de una edad mínima o máxima. La autoridad central del estado de recepción tiene que constar que los solicitantes son adecuados y aptos para adoptar que incluye también que cumplen los requisitos legales como por ejemplo que se trate de una pareja casada.

${ }^{39}$ En unos casos quedará siempre el problema de constatar si la adopción tiene como efecto la ruptura del vínculo

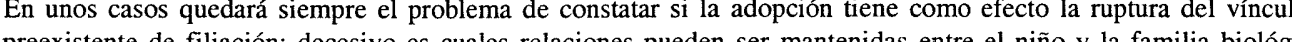

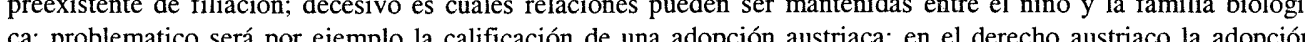
da al niño el estatus de hijo del adoptante y de sus descendientes, pero no en relación con los otros parientes de este; en cuanto al derecho sucesorio y alimenticio la relación con la familia bióónica no se rompe totalmente pero los derechos sucsorios y alimentios sen pero los derechos sas o

${ }^{40} \mathrm{El}$ estado que reconoce la adopción tiene que controlar solamente la validez formal del certificado, ver Parra. Aranguren, N. 408.

${ }^{41}$ Parra-Aranguren, N. 65

${ }^{42}$ Benicke, p. 331 ss.

${ }^{43}$ Parra-Aranguren, N. 337.

Revista da Faculdade de Direito da UFRGS, v. 21, Março/2002
La consecuencia del control de las exigencias legales por las dos autoridades centrales va a ser en la práctica, que los requisitos legales del estado de orígen como los del estado de recepción tienen que ser cumplidos $^{44}$. La autoridad central del estado de orígen aprecia las condiciones que un niño de este estado puede ser adoptado por las condiciones legales del mismo estado de orígen. Como ella tiene que dar su consentimiento de que el proceso de adopción continue, los requisitos legales del estado de orígen tienen que ser cumplidos también en el caso que la adopción se efectua en el estado de recepción. Al otro lado cuando la adopción se debe efectuar en el estado de orígen, ésto sólo se puede hacer si la autoridad central del estado de la recepción ha dado su acuerdo. Esta autoridad central examina siempre que los solicitantes cumplen los requisitos legales de estado de recepcíon. Es muy probable que en la práctica la autoridad central del estado de recepcíon verifique también que la prevista adopción cumple con todas las exigencias de la ley del estado de recepcíon. Porque una vez dictada la adopción en el país de origen, ella tiene que ser reconocida en el estado de recepción.

El proceso de cooperación tiene de esta forma como efecto, que los requisitos legales para la adopción, por ejemplo la edad mínima o máxima del adoptado y de los adoptantes, los consentimientos requeridos etc., tienen que ser cumplidos según los dos ordenes jurídicos involucrados.

Para evitar el impedimiento que resulta de esta aplicación doble de los derechos, los estados contractantes deberían reducir los requisitos formales para que una adopción pueda ser dictada. La importancia de los requesitos legales formales disminuye cuando hay un procedimiento intensivo en el cual se

${ }^{44}$ Benicke, p. 333 investiga y examania si el interés superior del niño amerita la adopción.

Si Alemania ratifica el convenio su ley interna de adopción tendría que ser transformada. Las reformas tendrían que hacerla más adecuada para los casos de adopciones internacionales. En la actualidad los consentimientos tienen que ser declarados frente de un notario público. Este documento que contiene dicha declaración debe ser transmitido al tribunal competente. De ahí surgen muchas complicaciones cuando los consentimientos se dieron en el extranjero. Parece suficiente para un proceso de adopción en Alemania que la autoridad central del estado de orígen certifique que los padres biológicos han consentido.

La ratificación del convenio tendría como consecuencia positiva que no sea necesario repetir las adopciones extranjeras desaparecerá. Hemos visto que el convenio contiene las siguientes claúsulas:

1 - El reconocimiento ex lege.

2 - La transformación limitada de una adopción plena.

3 - La certificación de la autoridad central del estado de origen . Así sólo en el caso de una adopción simple existiera una razón para repetirla en Alemania.

\section{Nuevas tendencias}

Antes de concluir quiero tematizar todavía una tendencia reciente en el derecho de adopción. En la primera mitad de este siglo la adopción fue concebida primordialmente como un medio de facilitar a personas, que no tenían hijos propios de procurarse un heredero para continuar la familia y el apellido. Este concepto 
explica que en aquellos tiempos casí todos los derechos exigieron una edad mínima del adoptante muy elevada. Con el tiempo la función de la adopción cambió. Actualmente el objetivo principal de la adopción consiste en procurar a un niño sin familia la posibilidad de crecer en un hogar que le dé la atención y el carino para que se pueda desarrollar sanamente ${ }^{45}$.

Como en el caso de la custodia la opinión dominante era que el bienestar del niño exigía la atribución del niño a una sola familia. Por consecuencia la preferencia se dió a la adopción plena que rompe 1a relación con la familia biológica en un a forma total ${ }^{46}$. Hoy en día la adopción plena ya no es vista como la única forma de adopción aconsejable. Se reconoce que en ciertos casos otras formas de adopción pueden ser más favorables para el hijo. Por ejemplo cuando el menor está en una edad más conciente al realizar la adopción, continuación de las relaciones con la familia biológica puede ser muy beneficiosa para la identidad del niño. Si los padre adoptivos lo pueden aceptar, forma abiertas de adopciones han comprobado se mejores para el niño. De ahí surge que la adopción simple se juzge actualmente má positiva ${ }^{47}$. En Inglaterra unos tribunale han acordado hasta un derecho de visit con los padres biológicos ${ }^{48}$.
La situación de ahora está caracterizada por la aceptación que una nueva flexibilidad es necesaria. En unos casos la adopción plena es la más adecuada, pero en otros una forma abierta con un derecho de visita parece más idónea. La aceptación de que el niño no tiene que ser extraido totalmente de la familia biológica tiene también un impacto en las adopciones internacionales. Esta causa muchas veces un cambio total en la cultura del niño. Adopciones de una forma más abierta pueden dar la posibilidad de que el niño crezca con una familia adoptiva en otro continente sin perder su propia identidad cultural.

\section{Conclusiones}

El convenio relativo a la protección del niño y a la cooperación en materia de adopción internacional de La Haya forma parte de los convenios modernos. El reglamento central consiste en la cooperación de entidades administrativas de los estados contractantes. No tiene como objeto primordial la uniformidad del derecho interno o internacional privado de la adopción.
La cooperación obligatoria de las autoridades centrales responde a las demandas del estado de orígen del menor como a las demandas del estado de recepión del menor de controlar las adopciones. Además la intermediación obligatoria puede servir como un mecanismo eficaz para luchar contra el tráfico ilegal de menores y presta al mismo tiempo el acompanamiento social y psicológico tan importante para las adopciones internacionales. El impedimento que los tramites de cooperación y intermediación producen se justifica para llevar a cabo una mejor protección del menor.

El convenio contiene también reglas que pueden facilitar el reconocimiento de adopciones extranjeras y por medio de una rasformación limitada mejora la posición del niño adoptado.

Alemania debería ratificar el convenio ${ }^{49}$. La ratificación tendría que ser acompañada de una reforma de la ley interna de la adopción para que éste puede responder mejor a los casos de adopciones internacionales.

${ }^{45}$ Gernhuber/Coester-Waltien, Familienrecht, 4. ed. Muenchen 1994, p. 350.

${ }^{46}$ Baer, Adoptees searching for their Origins: A New Development seen from an International Standpoint, en Eekelar/Sarcevic (ed.), Parenthood in Modern Society, Dordrecht 1993, p. 247.

${ }^{47}$ Jayme, p. 242: La adopción plena pone en peligro la identidad cultural del menor; Rubellin-Dechivi, Permanence et modernité de l'adoption après la loi du 5 juillet 1996, La Semaine Juridique (Éd. G.), 3979 (doctrine), p. 452 sobre la revalorización de la adopción simple por el legislador frances.

${ }^{48}$ Ver los casos citados por Mendoza, Adoption Case-Law Review, Family Law 1996, p. 681 ss. 